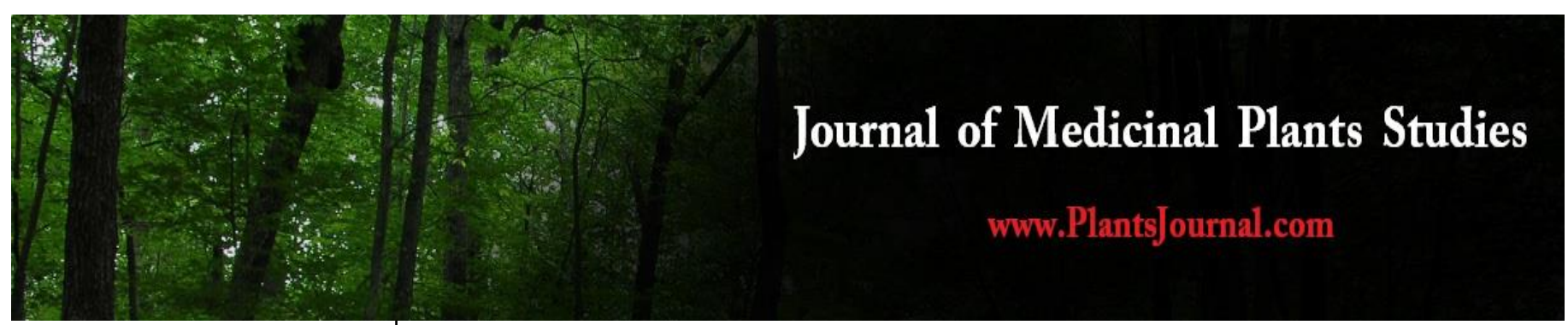

ISSN (E): 2320-3862

ISSN (P): 2394-0530

www.plantsjournal.com

JMPS 2021; 9(3): 105-110

(C) 2021 JMPS

Received: 04-01-2021

Accepted: 08-03-2021

NNG Chiranthika

Department of Food Science and

Technology, Faculty of

Livestock, Fisheries and

Nutrition, Wayamba University

of Sri Lanka, Makandura,

Gonawila, (NWP), Sri Lanka

Ananda Chandrasekara

Department of Applied

Nutrition, Faculty of Livestock,

Fisheries and Nutrition,

Wayamba University of Sri

Lanka, Makandura, Gonawila,

(NWP), Sri Lanka

KDPP Gunathilake

Department of Food Science and

Technology, Faculty of

Livestock, Fisheries and

Nutrition, Wayamba University

of Sri Lanka, Makandura,

Gonawila, (NWP), Sri Lanka

Corresponding Author: KDPP Gunathilake

Department of Food Science and

Technology, Faculty of

Livestock, Fisheries and

Nutrition, Wayamba University

of Sri Lanka, Makandura,

Gonawila, (NWP), Sri Lanka

\section{In vitro $\alpha$ amylase and amyloglucosidase inhibitory activities of selected underutilized cereals, yams and root crops}

\section{NNG Chiranthika, Ananda Chandrasekara and KDPP Gunathilake}

\author{
DOI: https://doi.org/10.22271/plants.2021.v9.i3b.1271
}

\section{Abstract}

Diabetes is one of the most challenging global health problems. Currently, reducing postprandial blood glucose concentration by inhibiting carbohydrate hydrolyzing enzymes is recognized as an effective treatment against diabetes. In this study, in vitro $\alpha$-amylase and amyloglucosidase inhibitory effect of selected, underutilized and locally grown cereals ( $P$. miliaceum, $P$. scrobiculatum and $S$. italica), yams (D. alata and D. esculenta) and root crops (L. spinosa and N. nucifera) were evaluated related to their dietary fiber contents. Results showed that the inhibitory effect of selected food crops has a positive correlation with their dietary fiber contents. L. spinosa with higher dietary fiber content generally had higher $\alpha$-amylase (78.0\%) and amyloglucosidase (71.28\%) enzyme inhibitory percentages among yams and root crops. Significantly highest $(p<0.05)$ dietary fiber content was in $S$. italic among three cereal varieties and it showed the highest inhibition activity against $\alpha$-amylase $(67.8 \%)$ and amyloglucosidase $(59.40 \%)$ activity. These tested food crops are considerable sources of dietary fiber and are having $\alpha-$ amylase and amyloglucosidase enzyme inhibitory actions against starch hydrolysis.

Keywords: $\alpha$ amylase inhibition, amyloglucosidase inhibition, cereals, root, yams

\section{Introduction}

Diabetes mellitus is one of the most common chronic non-communicable diseases characterized by elevated fasting blood glucose levels $(\geq 125 \mathrm{mg} / \mathrm{dl}){ }^{[1]}$. Elevation of blood glucose concentration occurs either due to pancreatic $\beta$ cells does not secrete enough insulin enzyme (type I diabetes mellitus) or cells in the human body do not properly respond to the produced insulin (type II diabetes mellitus). American Diabetes Association reported as around 90-95\% of identified diabetes cases are related to type II diabetes mellitus (American Diabetes Association ${ }^{[2]}$ ). Diabetes mellitus is prevailing all over the world and it is predicted to be one of the main death causes disease in the next two to three decades. The most diagnosed cases are from Asia and Africa region and the accelerating rate of diabetes mellitus is expected to increase by two to three folds by $2030{ }^{[3]}$. It impresses the important and urgent requirement of controlling or preventing diabetes mellitus conditions among people. The control of postprandial blood glucose elevation is one of the efficient methods in the management of diabetes mellitus [4]. The management of post-prandial blood glucose concentration is associated with the inhibition of starch hydrolysis enzymes such as $\alpha$ amylase and amyloglucosidase ${ }^{[5]}$. $\alpha$ Amylase enzyme hydrolyzes the $\alpha$ 1-4 linkages in starch and convert high molecular weight starch into simple and more absorbable compounds such as glucose, maltose and maltotriose. Subsequently, the amyloglucosidase enzyme is responsible to convert all the simple molecules of starch into glucose ${ }^{[6]}$. By inhibition of these enzyme activities, it will induce the delaying or decreasing the starch digestion which is important in controlling diabetes mellitus. Some synthetic inhibitors such as acarbose and voglibose are clinically used to reduce the starch hydrolysis enzyme activities to reduce the postprandial blood glucose concentration. However, those synthetic medicines have been shown side effects such as diarrhea, abdominal pain and hypoglycemia and with prolonged treatment, the drug resistance to these medicines has been reported from diabetes patients ${ }^{[3]}$. Therefore, apart from currently available medications, the naturalmedicines from plant sources have obtained more importance, since they are not much expensive and free from side effects compared to synthetic diabetes control drugs ${ }^{[5]}$. In Sri Lanka, there are plenty of underutilized food crops importantly cereals, yams, and tuber crops which are not much systematically exploited regarding the anti-diabetes activity. 
Cereals, yams, and root crops contained several types of phytochemicals which are reported to having therapeutic effects against diabetes mellitus ${ }^{[7-10]}$. Whole grain cereals, yams and root crops have consisted of dietary fiber, including soluble dietary fiber and insoluble dietary fiber ${ }^{[11]}$. Several researchers have documented the relationship between dietary fiber intake and a decrease in glycemic response in diabetes mellitus ${ }^{[12]}$. This study will reflect the effect of the dietary fiber content of selected food crops on in vitro $\alpha$ amylase and amyloglucosidase enzyme inhibition action with the means of controlling diabetes mellitus. The findings may be important when applying those selected food crops in functional food formulations for delivering additional health benefits to the consumers.

\section{Materials and Methodology \\ 2.1 Materials}

Three yam varieties of D. alata (Kahata-ala/KA, \& Hingurala/H) and D. esculenta (Java-ala/JA) were harvested from Hambantota area in Sri Lanka and N. nucifera (Lotus root) and L. spinosa (Lasia root), Panicum miliaceum (Proso millet), Paspalum scrobiculatum (Kodo millet) and Setaria italica (Foxtail millet) were purchased from the local market in Hambantota area in Sri Lanka. Porcine pancreatic $\alpha$ amylase, amyloglucosidase, dinitro salicylic acid, sodium hydroxide, sodium potassium tartrate, sodium phosphate, disodium orthophosphate, acetone, ethanol, sodium chloride and celite were purchased from Sigma (Sigma Co., St. Louis, MO, USA). All the chemicals and reagents procured were analytical grade.

\subsection{Sample preparation}

All three cereal grains ( $P$. miliaceum, $P$. scrobiculatum and $S$. italica) were de-hulled and grounded using a grinder (Philips HL772, Thailand) followed by sifted through $450 \mu \mathrm{m}$ sieves. All five types of roots and tubers (D. alata (KA, \& H), D. esculenta-JA, L. spinosa and $N$. nucifera) were washed, peeled and removed defective parts followed by cut into thin slices (thickness $\sim 3 \mathrm{~mm}$ ) and immediately soaked in $2 \%$ citric acid solution for 20 minutes (Bindu, Mythili, \& Radhika, 2018) and dried using hot air oven (MEMMERT NLE 500, Germany) at $45^{\circ} \mathrm{C}$ for $48-72 \mathrm{hrs}$. The dried pieces were grounded using a laboratory-scale grinder (Philips HL772, Thailand) and sifted through a $450 \mu \mathrm{m}$ sieve. Flour samples were packed and stored at $-20{ }^{\circ} \mathrm{C}$ for further analysis.

\subsection{Total Dietary fiber analysis}

Total dietary fiber content was analyzed using the modified enzymatic-gravimetric procedure as mentioned in Prosky, (1979) ${ }^{[13]}$. One gram of sample from each was weighed into a $600 \mathrm{~mL}$ beaker and $50 \mathrm{~mL}$ of phosphate buffer $(\mathrm{pH}$ 6.0) was added to each beaker. Then the samples were heated after adding $100 \mu \mathrm{L}$ of heat-stable alpha-amylase at $95{ }^{\circ} \mathrm{C}$ for 15 minutes and then samples were digested with $5.0 \mathrm{mg}$ of protease for 30 minutes at $60{ }^{\circ} \mathrm{C}$. Then $0.3 \mathrm{~mL}$ of amyloglucosidase was added and incubated at $60{ }^{\circ} \mathrm{C}$ for 30 minutes in a water bath. 95\% ethanol (four volumes) was added to precipitate dietary fiber and kept overnight. Then the solution part was filtered out through the crucible and precipitate was washed off using $20 \mathrm{~mL}$ portions of $78 \%$ ethanol, 95\% ethanol and acetone two times accordingly. The precipitate was then oven-dried at $105{ }^{\circ} \mathrm{C}$ overnight in a hot air oven (MEMMERT NLE 500, Germany) and then weighed. Values obtained by the enzymatic method were then corrected by analyzing protein and ash in the samples.

\subsection{In vitro $\alpha$ amylase inhibitory assay}

In vitro $\alpha$ amylase activity was measures using the method described in Xiong et al., (2020) ${ }^{[14]}$ with some modifications as mentioned in Mel et al (2020) ${ }^{[15]}$ and Janarny and Gunathilake, (2020) ${ }^{[16]}$. A sample of $1.00 \mathrm{mg}$ from each yam, roots and cereal flours were weighed and $100 \mu \mathrm{l}$ of the $\alpha$ amylase enzyme was added which was prepared by adding $27.5 \mathrm{mg}$ of enzyme in $100 \mathrm{~mL}$ of $20 \mathrm{mmol}$ sodium phosphate buffer containing $6.7 \mathrm{mmol}$ of sodium chloride was added (pH 6.9). Then the reaction mixture was pre-incubated at 37 ${ }^{\circ} \mathrm{C}$ for $20 \mathrm{~min}$. Then the $1 \%$ starch solution was prepared and $100 \mu \mathrm{l}$ of the starch solution was added into the reaction mixture before incubating it again at $37{ }^{\circ} \mathrm{C}$ for $10 \mathrm{~min}$. At the end of the incubation $200 \mu \mathrm{l}$ of dinitro salicylic acid solution was added to colour development followed by keeping the test tubes in a boiling water bath for $5 \mathrm{~min}$ to terminate the reaction. Then the reaction mixture was diluted with $2.20 \mathrm{~mL}$ of distilled water and absorbance was read at $540 \mathrm{~nm}$ by UV/Visible spectrophotometer (Thermo Scientific 201, United State). The experiments were conducted in triplicates and the absorbance of blank, control was measured.

\subsection{In vitro amyloglucosidase inhibition assay}

The In-vitro amyloglucosidase inhibition activity of selected cereals, tubers and root flours was determined according to the method in Si et al, (2020) ${ }^{[17]}$ with slight modifications. A sample of $1.00 \mathrm{mg}$ from each yam, roots and cereal flours were weighed and added into test tubes. Freshly diluted amyloglucosidase to $6.5 \mathrm{U} / \mathrm{mL}$ in $0.1 \mathrm{M}$ sodium phosphate buffer was added to each tube and followed by incubated in a water bath at $37{ }^{\circ} \mathrm{C}$ for $20 \mathrm{~min}$. Subsequently, $20 \mu \mathrm{L}$ of $1 \%$ starch solution was added as the substrate to each reaction mixture and incubated at $37{ }^{\circ} \mathrm{C}$ for $10 \mathrm{~min}$. Then $100 \mu \mathrm{L}$ of dinitro salicylic acid (color reagent) was added into the test tube and incubated at $100{ }^{\circ} \mathrm{C}$ for $5 \mathrm{~min}$. Then reaction mixtures were cooled in an ice-water bath before adding 2.5 $\mathrm{mL}$ of distilled water to dilute the reaction mixture. The absorbance of each reaction mixture was measured at $540 \mathrm{~nm}$ using a UV/Visible spectrophotometer (Thermo Scientific 201, United State). A blank was prepared to replace amyloglucosidase and $1 \%$ starch solution with sodium phosphate buffer. Control was prepared by replacing the amyloglucosidase enzyme with sodium phosphate buffer.

\subsection{Statistical Analysis}

All the analyses were conducted in triplicate and the data were expressed as mean \pm standard deviation. The sample means were compared at the 95\% confidence level $(p<0.05)$ using the Tukey's test in SPSS 16.0 software.

\section{Results and Discussion}

The data in Table 1 reflect the dietary fiber contents of $P$. miliaceum, P. scrobiculatum, S. italica, D. alata (KA, \& H), D. esculenta-JA, L. spinosa and N. nucifera.

Table 1: Dietary fiber contents of selected cereal, yams and root crops

\begin{tabular}{|c|c|}
\hline Crop & $\begin{array}{c}\text { Dietary fiber content } \\
\text { (g/100 g in dry weight basis })\end{array}$ \\
\hline D. alata-KA & $11.75 \pm 0.26^{\mathrm{d}}$ \\
\hline D. alata- H & $6.83 \pm 0.66^{\mathrm{a}}$ \\
\hline D. esculenta-JA & $36.06 \pm 0.37^{\mathrm{f}}$ \\
\hline L. spinosa & $14.36 \pm 0.27^{\mathrm{e}}$ \\
\hline N. nucifera & $39.42 \pm 0.74^{\mathrm{g}}$ \\
\hline P. miliaceum & $8.70 \pm 0.12^{\mathrm{c}}$ \\
\hline P. scrobiculatum & $8.11 \pm 0.14^{\mathrm{b}}$ \\
\hline S. italica & $14.18 \pm 0.32^{\mathrm{e}}$ \\
\hline
\end{tabular}

Values expressed as means \pm SD $(n=3)$. Different letter superscripts express significant differences between values of the same column $(\mathrm{p} \leq 0.05)$. 
When considering total dietary fiber contents in yams and root crops, L. spinosa root $(39.42 \%)$ and D. esculenta-JA $(36.06 \%)$ showed significantly higher value $(\mathrm{p} \leq 0.05)$ compared to the other three varieties. It is reported as a mucilaginous fraction of yams that contains soluble glycoprotein and dietary fiber ${ }^{[7]}$. It was visually observed in D. esculenta-JA, containing a higher amount of mucilage and it may be the reason for comparatively higher dietary fiber content. There is evidence showing $L$. spinosa root contain a higher amount of dietary fiber which was compatible with the present study and it has been evaluated the dietary fiber content of $L$. spinosa root using six samples from six different geographical areas and dietary fiber content was in the range of $40-74 \%$ in dry weight basis ${ }^{[18]}$. Another researcher presented the dietary fiber content of L. spinosa root as $45.34 \%$ that is also linear with our results ${ }^{[19]}$. The total dietary fiber contents of three Dioscorea varieties were in the range of $6.83-36.06 \%$. The previously presented data for total dietary fiber contents of $16 \mathrm{D}$. alata species were in the range of 4.1 to $11 \%$ as in Wireko-manu et al., (2009) ${ }^{[20]}$ and however, the value obtained for the D. esculenta-JA in the present study was much higher $(36.06 \%)$. The dietary fiber content of $N$. nucifera roots in this study was higher than the value $(11.85 \%)$ obtained by Ham et al ${ }^{[21]}$. The total dietary fiber contents of three whole grain millet species were 8.70, 8.11 and $14.18 \%$ in P. miliaceum, P. scrobiculatum and $S$. italica respectively. When comparing dietary fiber contents of three selected cereals, a significantly higher value was observed in S. italica.

The following two graphs (Figure 1 and Figure 2) show the $\alpha$ amylase and amyloglucosidase enzyme inhibition activity\% observed from selected three cereal crops and five yams and root crops respectively.

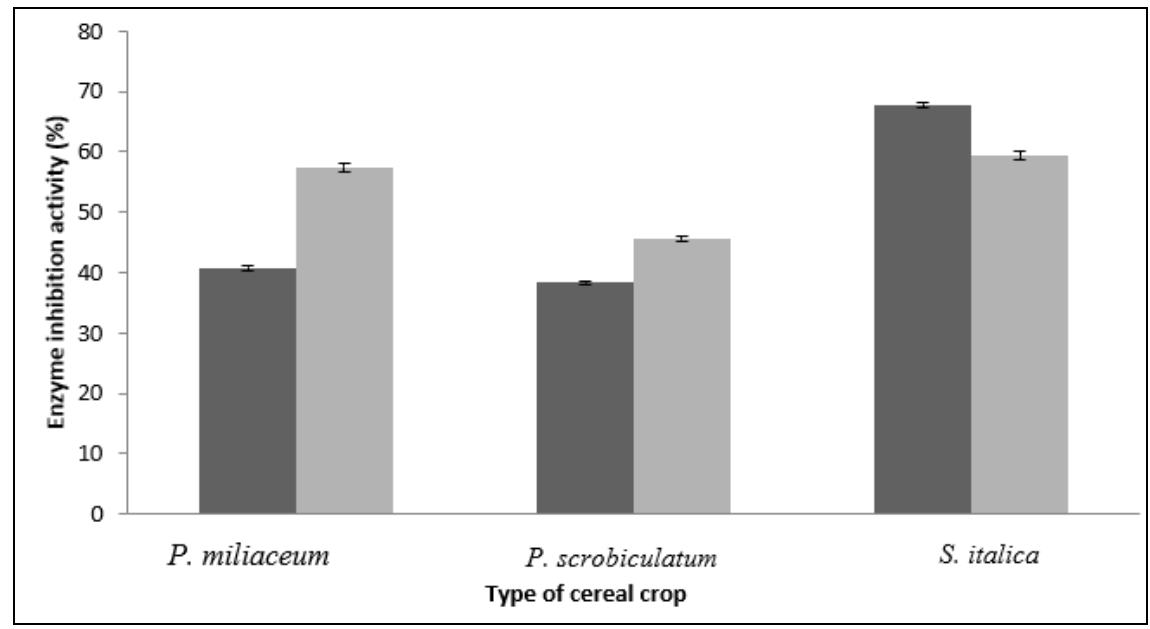

Fig 1: $\alpha$ amylase and amyloglucosidase inhibitory activity of selected cereals; $P$. miliaceum, $P$. scrobiculatum and $S$. italica. inhibition\%, -Amyloglucosidase inhibition\%). The data are indicated as the mean \pm standard deviation $[\mathrm{n}=3]$.



Fig 2: $\alpha$ amylase and amyloglucosidase inhibitory activity of selected yams and root crops $(\square-\alpha$ amylase inhibition $\%$, $\square$-Amyloglucosidase inhibition $\%)$. The data are indicated as themean \pm standard deviation $[\mathrm{n}=3]$.

Enzymes are considered as a protein-based biological catalyst which can regulate the specific biochemical reactions. $\alpha$ amylase enzyme found in the human digestive tract can breakdown $\alpha, 1-4$ glycosidic bonds in the amylose and amylopectin chains in starch. $\alpha$ amylase enzyme can convert above the substrate to oligosaccharides mainly. Since this enzyme act on both amylose and amylopectin, it can produce particular end products as maltotriose and maltose from 
amylose and maltose, glucose and limit dextrin from amylopectin ${ }^{[22]}$. Amyloglucosidase is also a starch hydrolyzing enzyme that cleavage the $\alpha 1-4$ glycosidic bonds from the non reducing ends of starch and release glucose molecules. Further, amyloglucosidase can catalyze the releasing of $\beta$-d-glucoseby cleavage $\alpha-1,4$ and $\alpha-1,6$ linkagesin non-reducing ends of starch and maltooligosaccharides to produce glucose ${ }^{[23]}$. After food intake, the $\alpha$ amylase action will take place and it can increase the postprandial blood glucose level in diabetic patients since $\alpha$ amylase can convert starch into simple and more absorbable forms. This phenomenon can be controlled or regulated by inhibiting the $\alpha$ amylase activity. Apart from using synthetic medicines to achieve that it is very important to reveal the possibility of foods themselves to control diabetes conditions. According to the obtained results for $\alpha$ amylase inhibition activity of selected three cereal varieties, the values were as $40.80 \pm 0.43,38.31 \pm 0.21$ and $67.80 \pm 0.48 \%$ in $P$. miliaceum, $P$. scrobiculatum and $S$. italica respectively. According to the obtained results, $S$. italica showed the highest significant percentage $(\mathrm{p} \leq 0.05)$ of $\alpha$ amylase inhibition activity. $P$. miliaceum, $P$. scrobiculatum were also showed considerable inhibitory activity. However, only $S$. italica has shown more than $50 \%$ inhibition action. The amyloglucosidase inhibition activity of $P$. miliaceum, $P$. scrobiculatum and $S$. italica was ranged from $45.54 \pm 0.45$ to $59.40 \pm 0.81 \%$. The highest amyloglucosidase inhibition activity was observed in $S$. italica as similar observation in the $\alpha$ amylase inhibition activity while, $P$. miliaceum, $P$. scrobiculatum have shown $57.42 \pm 0.62$ and $45.54 \pm 0.45 \%$ of amyloglucosidase inhibitory action respectively. When considering the in vitro enzyme inhibition activities resulted from yams and root crops together, the values were significantly different $(\mathrm{p} \leq 0.05)$ in both assays. According to the results indicated in Figure 2, all yams and root crop varieties D. alata-KA, D. alata- $H, D$. esculenta-JA, L. spinosa and $N$. nucifera showed considerable inhibition activities. According to the results obtained for $\alpha$ amylase inhibition activity, it was ranged from $30.87 \pm 0.54$ to $78.00 \pm 0.96 \%$ and L. spinosa showed the highest significant $(\mathrm{p} \leq 0.05) \alpha$ amylase inhibition activity among tested five yams and root crops samples. Amyloglucosidase enzyme inhibition activities of D.alata-KA, D.alata-H, D. esculenta-JA, L. spinosa and $N$. nucifera were as $35.14 \pm 0.56,46.53 \pm 0.37$, $69.30 \pm 0.87,71.28 \pm 0.32$ and $61.38 \pm 0.54$. Percentage inhibition of amyloglucosidase enzyme activity was also significantly higher in $L$. spinosa compared to other yams and roots. The significantly lowest $(\mathrm{p} \leq 0.05) \alpha$ amylase inhibition activity was found in D. alata-H while D.alata-KA showed the lowest amyloglucosidase inhibition action. According to a previous study, The ethanolic extracts of $P$. miliaceum and $S$. italicahave shown $\alpha$ amylase inhibitory action and they reflect the effect of the phenolic compound on that inhibition potential ${ }^{24}$. Reddy and others investigated $\alpha$ amylase inhibition activity of $P$. scrobiculatum and reported it has remarkable inhibition activity ${ }^{[25]}$. However, supporting information for the present study's data could not found due to a lack of literature that discussing the $\alpha$ amylase inhibition and amyloglucosidase inhibition activities in terms of dietary fiber content in selected food crops.

Figure 3 and Figure 4 reflect the correlation between dietary fiber content and assessed enzyme inhibitory activities of yams and root crops, and cereal varieties accordingly.

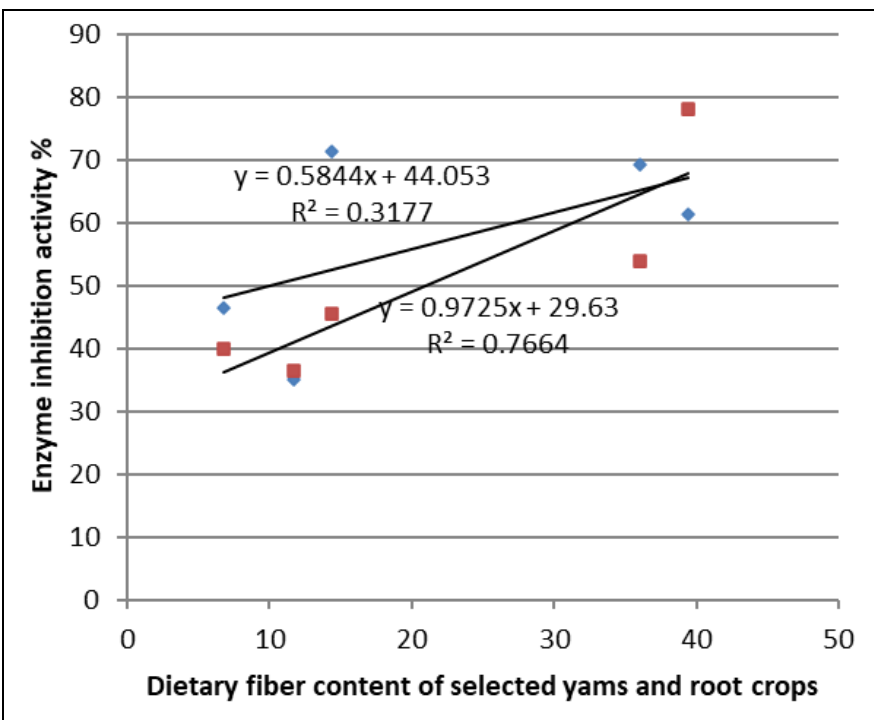

Amyloglucosidase inhibition \%

$\alpha$-amylase inhibition $\%$

Fig 3: Correlation between dietary fiber content and enzyme inhibition activity $\%$ of selected yams and root crops

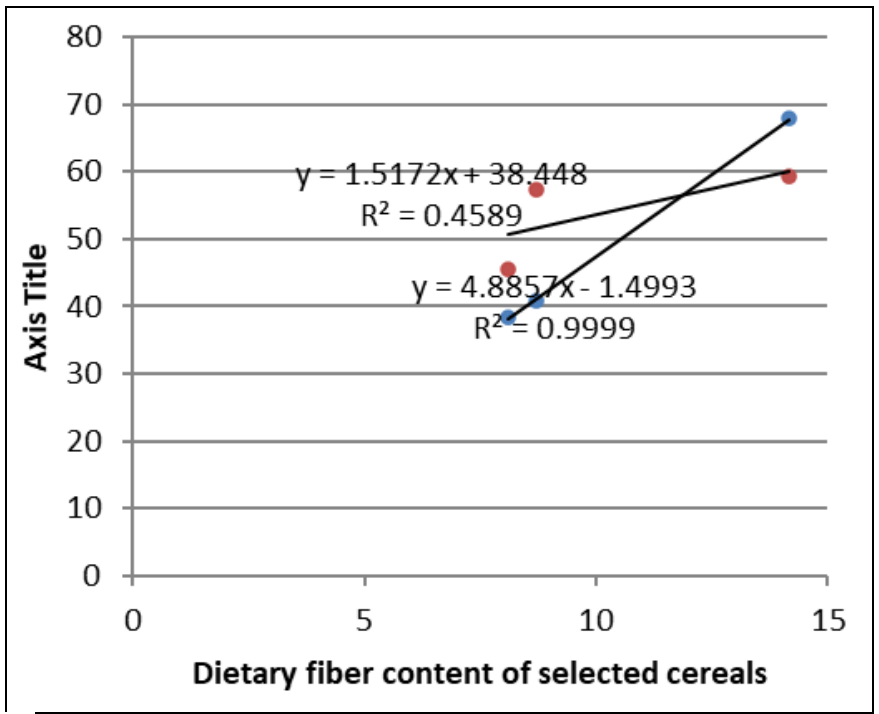

Amyloglucosidase inhibition \%

$\alpha$-amylase inhibition $\%$

Fig 4: Correlation between dietary fiber content and enzyme inhibition activity $\%$ of selected cereal crops

The correlation between dietary fiber content and $\alpha$ amylase and amyloglucosidase enzyme inhibitory percentages were analyzed separately for yams and roots, and cereals. According to the obtained results, the correlation between the dietary fiber content of yams and roots with $\alpha$ amylase inhibitory action showed $\left(\mathrm{R}^{2}=0.3177\right)$ a positive weak correlation. Meanwhile, the relationship between the dietary fiber content of yams and roots with amyloglucosidase inhibitory action showed a strong positive correlation $\left(\mathrm{R}^{2}=\right.$ 0.7664). When considering the correlation pattern of $\alpha$ amylase inhibition activity of $P$. miliaceum, $P$. scrobiculatum and $S$. italica and their dietary fiber contents, it showed a very strong positive correlation $\left(\mathrm{R}^{2}=0.9999\right)$ and the correlation regression value for dietary fiber content and amyloglucosidase inhibition activity of tested cereals was $\mathrm{R}^{2}$ $=0.4589$, categorized as a moderate positive correlation. 
All four tested correlation patterns were showed positive correlation and their correlation levels were interpreted as weak, strong, very strong and moderate according to Schober and Boer, (2018) ${ }^{[26]}$. The resulted in positive correlation from tested eight food crops under cereals, yams and roots reflect, the increased dietary fiber content potent to increase the $\alpha$ amylase and amyloglucosidase enzyme inhibition activity. Qi and the group have shown a positive correlation between rice bran insoluble dietary fiber and $\alpha$ amylase inhibitory activity [27]. The influence of wheat bran dietary fiber against $\alpha$ amylase enzyme activity has been reported by $\mathrm{Ou}$ et al., 2001.There are a few suggested pathways or mechanisms of enzyme inhibition activity by dietary fiber. Meng et al., 2019 reported the positive correlation between dietary fiber of buckwheat straw with $\alpha$ amylase inhibition activity. Ou et al., (2001) ${ }^{[28]}$ reported as dietary fibers can be adsorbed to starch in the food and disturbing the hydrolysis of starch by hydrolytic enzymes such as $\alpha$ amylase and dietary fiber act as a physical barrier in between starch and hydrolysis enzymes which hinder the reaction between starch and enzymes. Several reports discussed the overall capability of reducing the risk of diabetes mellitus by dietary fiber intake and the suggested mechanisms. One of them is by reducing the gut transit time especially by soluble dietary fiber leads to reduce starch digestion in the small intestine and they are transferred into the large intestine quickly ${ }^{[29]}$. The other view was the dietary fiber can increase the viscosity of content in the small intestine and reduce the accessibility of enzymes to the substrate (starch) ${ }^{[30]}$.

\section{Conclusion}

In conclusion, our investigation demonstrated that we tested P. miliaceum, P. scrobiculatum, S. italica, D. alata (KA, \& H), D. esculenta-JA, L. spinosa and N. nucifera exhibited significant in vitro inhibitory activity against $\alpha$-amylase and amyloglucosidase enzymes. The extent of inhibition was related to the dietary fiber contents. L. spinosa sample with higher dietary fiber content generally had significantly higher $(\mathrm{p} \leq 0.05) \alpha$-amylase and amyloglucosidase enzyme inhibitory percentages among yams and root crops. Significantly highest $(p<0.05)$ inhibition activities against $\alpha$-amylase and amyloglucosidase were shown by $S$. italica sample and the highest dietary fiber content also was in $S$. italica among three cereals. The findings may important to generalize these selected underutilized sources as good dietary fiber sources and their potential enzyme inhibitory activity against starch hydrolysis which leads to reduce the risk of diabetes mellitus. Further, incorporation of these dietary fiber sources into food formulation and producing functional food products may lead to giving additional health benefits to the consumers. However, further investigation needs to be done related to the hypoglycemic activity of these crops by different in vitro and in vivo assays to confirm their anti-diabetic potential and action.

\section{Acknowledgements}

We greatly acknowledge the financial support provided by World Bank AHEAD project under the research grant AHEAD/RA3/DOR/WUSL/FST.

\section{References}

1. World Health Organization. Definition and diagnosis of diabetes mellitus and intermediate hyperglycaemia: report of a WHO/IDF consultation 2006.

2. American Diabetes Association. Standards of Medical
Care in Diabetes 2010, 33. https://doi.org/10.2337/dc10S011.

3. Ghosh S, Ahire M, Patil S, Jabgunde A, Dusane MB, Joshi BN et al. Antidiabetic Activity of Gnidia glauca and Dioscorea bulbifera: Potent Amylase and Glucosidase Inhibitors 2012. https://doi.org/10.1155/2012/929051

4. Nsor-atindana J, Goff HD, Saqib N, Chen M, Liu W, Ma $\mathrm{J}$, et al. Inhibition of $\alpha$-amylase and amyloglucosidase by nanocrystalline cellulose and spectroscopic analysis of their binding interaction mechanism. Food Hydrocolloids 2019. https://doi.org/10.1016/j.foodhyd.2018.12.031

5. Banerjee A, Maji B, Mukherjee S, Chaudhuri K, Seal T. In vitro anti-diabetic and anti-oxidant activities of ethanol extract of tinospora sinensis, International Journal of Current Pharmaceutical Research 2017;9(2):2-7, DOI: http://dx.doi.org/10.22159/ijcpr.2017v9i2.17379

6. Frederick A, Bin JW, Gina Z, Michael W, Dhital JGS. The interplay of $\smile$-amylase and amyloglucosidase activities on the digestion of starch in vitro enzymic systems, Carbohydrate Polymers 2014. https://doi.org/10.1016/j.carbpol.2014.09.043

7. Chandrasekara A, Kumar TJ. Roots and Tuber Crops as Functional Foods: A Review on Phytochemical Constituents and Their Potential Health Benefits, International Journal of Food Science 2016, http://dx.doi.org/10.1155/2016/3631647.

8. Devi PB, Vijayabharathi R, Sathyabama S. Health benefits of finger millet (Eleusine coracana L.) polyphenols and dietary fiber: a review 2014;51:10211040. https://doi.org/10.1007/s13197-011-0584-9

9. Hettiarachchi HACO, Prasadi VPN, Adikari AMMU, Gunathilake KDPP. Granule Morphology and Physicochemical Properties of Flours of Three Yams Species: Colocasia esculenta, Xanthosoma sagittifolium and Plectranthus rotundifolius. South Asian Research Journal of Natural Products 2020, 18-30.

10. Wijesinghe HDKC, Gunathilake KDPP. Characterization and comparison of alkali extracted starches from selected cereals and tubers. Asian Plant Research Journal 2020, 112.

11. Chiranthika NNG, Gunathilake KDPP, Chandrasekara A. Potential Applications of Cereals and Yams as Functional Foods to Reduce the Risk of Chronic NonCommunicable Diseases 2020;7(4):53-69. https://doi.org/10.9734/AJRB/2020/v7i430148

12. Mogoş T, Dondoi C, Iacobini AE. A review of dietary fiber in the diabetic diet, 162, Romanian Journal of Diabetes Nutrition \& Metabolic Diseases 2017;24(2):161-164. https://doi.org/10.1515/rjdnmd2017-0021

13. Prosky L. Analysis of Total Dietary Fiber: The Collaborative Study 1979, 1-16. L. https://doi.org/10.1007/978-1-4613-2111-8_1

14. Xiong Y, Ng K, Zhang P, Warner RD, Shen S, Tang H, et al. Activities of Free and Bound Phenolic Extracts from the Bran and Kernel Fractions of Five Sorghum Grain Genotypes. Foods 2020;9:1301. doi:10.3390/foods9091301

15. Mel MMRD, Gunathilake KDPP, Fernando CAN. Formulation of microencapsulated rutin and evaluation of bioactivity and stability upon in vitro digestive and dialysis conditions. International journal of biological macromolecules 2020;159:316-323.

16. Janarny G, Gunathilake KDPP. Changes in rice bran 
bioactives, their bioactivity, bioaccessibility and bioavailability with solid-state fermentation by Rhizopus oryzae. Biocatalysis and Agricultural Biotechnology 2020;23:101510.

17. Si H, Koh A, Lu J, Zhou W. Structural Dependence of Sulfated Polysaccharide for Diabetes Management: Fucoidan From Undaria pinnati fi da Inhibiting a Glucosidase More Strongly Than a - Amylase and Amyloglucosidase, Frontiers in Pharmcology, 2020;11:19. https://doi.org/10.3389/fphar.2020.00831

18. Shefana G. Some nutritional aspects of Lasia spinosa (kohila), Vidyodaya Journal of Science, 2008, 59-64.

19. Shafie NH, Idris SL, Hamdan NN, Bakar SA, Ishak AH, Isa N. Nutritional Composition, Antioxidative and Inhibitory Effect Against Pancreatic Lipase, $\alpha$ Amylase and $\alpha$ Glucosidase of Lasia spinosa, Journal of Engineering \& Applied Sciences. 2018;13:8898-8905.

20. Wireko-manu FD, Maziya-dixon B, Robert A, Oduro IN. Nutritional and biochemical composition of $D$. alata (Dioscorea spp .) tubers, Journal of Food, Agriculture \& Environment 2009;7(2):373-378.

21. Ham Y, Hwang K, Song D, Kim Y, Shin D. Food Science of Animal Resources Lotus (Nelumbo nucifera) Rhizome as an Antioxi-dant Dietary Fiber in Cooked Sausage: Effects on Physicochemical and Sensory Characteristics, Korean Journal of Food Science of Animal Resources 2017, 219-227,

DOI https://doi.org/10.5851/kosfa.2017.37.2.219, .

22. Tiwari S, Srivastava R, Singh C, Shukla K, Singh R, Singh $\mathrm{P}$ et al. Amylases: an Overview With Special Reference To Alpha-Amylase, Journal of Global Biosciences 2015;4(1):1886-1901.

23. Adeoyo OR, Pletschke BI, Dames JF. Purification and characterization of an amyloglucosidase from an ericoid mycorrhizal fungus (Leohumicola incrustata). AMB Express 2018, 1-10. https://doi.org/10.1186/s13568-0180685-1

24. Kim JS, Hyun TK, Kim MJ. The inhibitory effects of ethanol extract from sorghum, foxtail millet and proso millet on $\alpha$-glucosidase and $\alpha$-amylase activities. Food Chemistry 2011;124(4):1647-1651. https://doi.org/10.1016/j.foodchem.2010.08.020

25. Reddy GJ, Reddy KB, Reddy GVS. In vitro $\alpha$-Amylase and $\alpha$-Glucosidase Inhibitory activity of extracts of Feronia elephantum fruit and Paspalum scrobiculatum Grains, Asian Journal of Pharmacy and Pharmacology; 2019;5(S1):42-47

DOI: https://doi.org/10.31024/ajpp.2019.5.s1.4 24552674/Copyright

26. Schober P, Boer C. Correlation Coefficients: Appropriate Use and Interpretation, Wolters Kluwer Health 2018. Inc.https://doi.org/10.1213/ANE.0000000000002864

27. Qi J, Li Y, George K, Shoemaker CF, Zhong F, Majeed $\mathrm{H}$, et al. Food Hydrocolloids The effect of chemical treatment on the In vitro hypoglycemic properties of rice bran insoluble dietary fiber. Food Hydrocolloids 2016;52:699-706. https://doi.org/10.1016/j.foodhyd.2015.08.008

28. Ou S, Kwok K, Li Y, Fu L. In Vitro Study of Possible Role of Dietary Fiber in Lowering Postprandial Serum Glucose, Journal of Agriculture Food Chemistry 2001, 491026-1029, https://doi.org/10.1021/jf000574n

29. Meng X, Liu F, Xiao Y, Cao J, Wang M, Duan X. Alterations in physicochemical and functional properties of buckwheat straw insoluble dietary fiber by alkaline hydrogen peroxide treatment. Food Chemistry: X 2019, 100029. https://doi.org/10.1016/j.fochx.2019.100029

30. Qi X, Al-Ghazzewi FH, Tester RF. Dietary fibre, gastric emptying and carbohydrate digestion: A mini-review, Journal of Starch 2017. doi: [10.1002/star.201700346] 